\title{
A 10-step guide to party conversation for bioinformaticians
}

\author{
Alicia Oshlack*
}

In Australia, December and January are part of the festive season. Summer is upon us and there is the mad preparation for Christmas while catching up with friends and family at barbecues, New Year's Eve parties and January beach holidays. At some social event or other (including ones at my own research institute) I inevitably get asked what I do. Responding with 'bioinformatics' is generally met with a blank stare or, in some cases, a slight edge towards a nearby door. Therefore, recently I have been working on tailoring my response so that at the end of an evening I still have people who are, firstly, willing to talk to me and, secondly, have some insight into what I do and why I find it interesting. Here I share a step-by-step guide that has helped me to convey some concept of my work to people not involved in the field, or even in science in general, when I am asked the question: 'So, what do you do?'

Step 1. Gauge whether the person actually wants to know the answer to the question. I usually dip my toes into the water with a response such as, 'I work in a medical research institute in a field called bioinformatics.' Then, if the person I am talking to is still looking interested, I might add, 'It is basically concerned with genetics and analyzing the masses of DNA data that we can produce.'

Step 2. Check if there is still interest in this conversation. Do not continue if the person is already looking around for another drink. Instead, start a conversation about the current woes of the Australian cricket team.

Step 3. If the person prods further, try to gauge their knowledge of science or genetics quickly with questions such as: 'So have you heard of DNA?'; 'Did you know that genes are actually parts of your DNA?'; and, 'Did you know that your DNA gets passed onto you from your parents, half from your mum and half from your dad?' Encourage them in their understanding of genetics after they tell you the story of their friend's neighbor's daughter

*Correspondence: alicia.oshlack@mcri.edu.au

Bioinformatics, Murdoch Childrens Research Institute, Royal Children's Hospital, Flemington Road, Parkville, Vic, Australia who was born with fused toes on her left foot that she inherited from her maternal grandmother.

Step 4. At this point introduce some conceptual feel for the size of the genome. Here is the analogy I have been working with. Your genome is your personal DNA sequence. DNA is a really long molecule that we represent with a string of letters which can be one of four types: A, T, G or C. The human genome has about 3 billion of these 'letters'. Now let me give you a feel for how big this really is. Imagine Tolstoy's very thick novel War and Peace. It has around 3 million letters in it, so the human genome has as many letters as 1,000 copies of War and Peace. If you were to pile this many copies of the paperback novel on top of each other you would form a stack about as high as an 18-storey building. There are a lot of letters in that stack and a lot of information that we are trying to understand. For example, a genetic disease is like having a typo in one of those copies of War and Peace.

Step 5. Smile and repeat Step 2.

Step 6. Introduce the next-generation sequencing revolution. Ten years ago it would have cost about $\$ 100$ million and taken many months to sequence a human genome and now it costs around $\$ 5,000$ and takes about 2 weeks. In order to achieve this we have to shatter the DNA into millions of small pieces and then we can sequence these fragments simultaneously. So this is like taking our 18-storey stack of War and Peace books, ripping out all the pages, shredding them into pieces that only contain a few hundred letters and simultaneously 'reading' the letters on each tiny piece of paper. As a result we have a huge pile of all the words and letters, but the trick is to try and put them back together correctly to make the original books. This can be quite a hard task and is really a computational and statistical challenge. You cannot do this by hand; you cannot even do this with an Excel spreadsheet!

Step 8. The silver bullet - at this point in the conversation you can begin to describe what you do. My job as a bioinformatician is to work with these data computationally and statistically in order to make sense of the DNA and understand what it means. We try and find the 'typo' in the genome that is related to disease. I see my 
job as the interface between our ability to generate data and our ability to understand what it is telling us about biology.

Step 9. Add examples of exciting discoveries from your own work (alternatively, if those groundbreaking discoveries are just around the corner, I like to claim examples from the literature). For instance, bioinformatics was recently used to discover that as men get older their sperm contain a larger number of DNA mutations that they can pass onto their kids. Or, recently this technology has been used to find DNA mutations in people with autism and to identify the genes involved. There are so many cool discoveries being made right now!

Step 10. If the conversation is going well and your new friend is mesmerized (yes, this has actually happened to me), then consider adding some extensions to the analogy. For example, one complication is that because War and Peace is a translation from the Russian novel there are in fact several different versions of the English novel. In a similar way, although we are all human we have many versions of DNA that make us all different.
Just because we see differences in our personal DNA sequence does not mean we have a typo - or a variation that causes disease. One of our jobs is to distinguish the millions of benign variations from typos that might be responsible for disease.

However, the most important element in this conversation is to convey that bioinformatics is an exciting, fascinating and high-paced field that has real potential to make a difference to people. I have found that over this festive season the 10-step guide has enabled me to engage people more often on topics that are of interest to me and that I actually know something about. Only occasionally have I had to divert the conversation at Step 2 and acknowledge the possibility that Australia is not certain to defeat the English in their own game this year.

Published: 29 January 2013

doi:10.1186/gb-2013-14-1-104

Cite this article as: Oshlack A: A 10-step guide to party conversation for

bioinformaticians. Genome Biology 2013, 14:104. 